\title{
Research Paper: Comparing the Width of Hamstring Grafts Prepared Using Wet and Dry Gauze Methods in Anterior Cruciate Ligament Reconstruction Surgery
}

\author{
Fardin Mirzatolooei $^{1}$ (D), Ali Tabrizi ${ }^{*}$ (D), Solmaz Gholizadeh ${ }^{2}$
}

1. Department of Orthopedics, Imam Khomeini Hospital, Urmia University of Medical Sciences, Urmia, Iran.

2. Student Research Committee, School of Medicine, Imam Khomeini Hospital, Urmia University of Medical Sciences, Urmia, Iran.

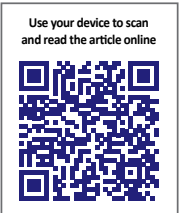

Citation Mirzatolooei F, Tabrizi A, Gholizadeh S. Comparing the Width of Hamstring Grafts Prepared Using Wet and Dry Gauze Methods in Anterior Cruciate Ligament Reconstruction Surgery. Journal of Research in Orthopedic Science. 2020; 7(4):153-158. http://dx.doi.org/10.32598/JROSJ.7.4.519.2

dof : http://dx.doi.org/10.32598/JROSJ.7.4.519.2

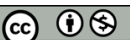

Article info:

Received: 05 Aug 2020

Revised: 25 Aug 2020

Accepted: 10 Oct 2020

Available Online: 01 Nov 2020

Keywords:

ACL reconstruction,

Hamstring graft,

Tunnel widening

\section{A B S T RA C T}

Background: The anterior cruciate ligament surgery commonly uses a hamstring tendon. The hamstring grafts are usually prepared by wrapping in a wet gauze under tension.

Objectives: The placement of a hamstring tendon in a dry gauze affects the size of the graft, without any change in its collagen volume. The present study aimed to prove that the preparation method could affect the hamstring graft width.

Methods: A total number of 32 patients who had undergone the anterior cruciate ligament reconstruction were enrolled in this analytical descriptive study. Initially, the width of the 4-layered extracted graft was measured using the sizer system, after placement under traction. Then, 16 patients were operated on, based on the dry gauze preparation method, and the other 16 , based on the wet gauze preparation method. The grafts were remeasured after traction. Six months after the surgery, all patients received a clinical evaluation, in which the integrity of the graft was evaluated based on clinical criteria.

Results: The Mean \pm SD width of the 4-layered extracted grafts was $7.44 \pm 0.54 \mathrm{~mm}$ and $7.41 \pm 0.33 \mathrm{~mm}$ in the dry gauze and wet gauze groups, respectively. However, these values did not significantly differ $(\mathrm{P}=0.96)$. After traction, the $\mathrm{Mean} \pm \mathrm{SD}$ graft width of the dry gauze group was reduced to $6.97 \pm 0.62 \mathrm{~mm}$. The traction led to no change in the graft width of the wet gauze group. The changes in the graft size significantly differed between the two groups $(\mathrm{P}=0.032)$. Moreover, 4 patients $(25 \%)$ exhibited no certain endpoint in the Lachman test, also, the pivot shift-test was positive in 5 patients $(31.2 \%)$.

Conclusion: The hamstring graft preparation technique affects the tunnel graft size. Besides, the use of dry gauzes procures the need for a narrower tunnel in the tibia and femur.

\footnotetext{
* Corresponding Author:

Ali Tabrizi, MD.

Address: Department of Orthopedics, Imam Khomeini Hospital, Urmia University of Medical Sciences, Urmia, Iran.

Phone: +98 (914) 3130829

E-mail:ali.tab.ms@gmail.com
} 


\section{Introduction}

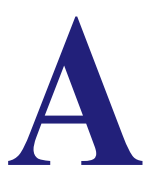

nterior Cruciate Ligament (ACL) reconstruction surgery is performed using varying methods, including Bone-Patellar Tendon-Bone (BPTB) autograft, hamstring tendon autograft, quadriceps autograft, and allografts [1]. Recently, the use of hamstring autograft has increased to enhance the performance and success rates [2-5]. Also, biomechanical studies have revealed that this graft is on par with or even superior to the BPTB grafts [6, 7]. Comparing BPTB and hamstring autografts, randomized clinical trials have reported similar findings [8-10].

Biomechanical studies have revealed that the durability of a tendon is directly correlated with its size; the smaller the size, the higher the chance of recurrent tearing in the grafted tendon. Some studies have reported the mean width of a 4-strand hamstring graft between $7.7 \mathrm{~mm}$ to $8.5 \mathrm{~mm}[6,7,11]$. However, clinical examinations and MR imaging revealed that the width of the hamstring muscle was highly variable throughout the population $[10,11]$. Although the accurate estimation of the width of hamstring muscles is difficult, it is directly correlated with height, sex, Body Mass Index (BMI), and knee circumference [12-15]. An array of techniques have been described to increase the final width of a standard hamstring removal [16-18]. Such techniques rely on increasing the hamstring fibers to increase the width of the removed graft.

Therefore, we propose that the width of a hamstring graft may vary between the dry preparations and when the graft is placed in liquid. If the results confirm the hypothesis that graft width decreases in dry preparations and increases in wet preparations, the lower degrees of graft-tunnel mismatch can be achieved. Hence, a narrower tunnel can be carved, and better stability and ligamentization can be achieved by placing a graft that will enlarge and fill the tunnel after the absorption of liquids. In this study, we designed a method to compare the impact of the wet and dry preparation methods on the graft width. Also, we aimed to assess the short-term clinical outcomes of these two preparation methods.

\section{Materials and Methods}

A total number of 32 patients candidate for ACL reconstruction were enrolled in an analytical descriptive study. All the procedures were reviewed and approved by the research ethics committee of our hospital, also, this study was carried out in accordance with the World Medical Association's Declaration of Helsinki. Writ- ten informed consent was obtained from all subjects, before participation. We enrolled all patients who had undergone the ACL reconstruction surgery owing to a torn ACL, within the first six months of 2017. The patients were divided into two groups and each group was subsequently operated on by following either of the two proposed preparation methods.

The patients were randomly divided into two matched groups; they were alternatively allocated into the groups by the time of administration. Following extraction, the hamstring grafts were folded into four layers and then placed within an ACL reconstruction work set (Zimmer Biomet, USA), under a traction of $15 \mathrm{~N}$. The work set is fitted with measuring equipment for the assessment of the width and length of the 4-layer graft (to the nearest $0.5 \mathrm{~mm}$ ). The two ends of the extracted graft were sutured using Ethibond suture, No. 2 (Johnson \& Johnson Medical NV, Belgium). Then, the grafts were placed under traction for five minutes and their widths were redetermined. Next, the grafts of each group were placed within the dry or wet gauzes. The width of the 4-layer graft was subsequently assessed (Figure 1). Also, sex, age, ethnicity, mechanism, time, BMI, and allocated grouping were recorded.

Wet gauzes were prepared by placing dry gauzes in a normal saline solution. No antibiotics were used in this method. The grafts were placed under the traction for 20 minutes, then, their sizes were reassessed using the same equipment. Subsequently, the tibial and femoral tunnels were created, based on the obtained measurements after 20 minutes of traction. The rest of the surgical procedure was routinely carried out and the same techniques were employed for both groups. In these operations, the fixedloop EndoButtons (Zimmer Biomet, USA) fixation devices and self-absorbing screws (Stryker Co.) were used for the femoral and tibial fixations, respectively. Six months after the surgery, all patients were reexamined and the anterior drawer test, the Lachman test, and the pivot-shift-test were obtained. Then, the variation in graft sizes and the clinical findings were compared between the two groups, using statistical methods.

\section{Statistical analysis}

The quantitative and qualitative data were expressed as Mean $\pm \mathrm{SD}$ and percentages, respectively. Besides, the paired t-test (in the case of normal distribution) or the Wilcoxon test (as a non-parametric test) was used to compare the average width of the grafts before and after the preparation. Moreover, the independent t-test (or the Mann-Whitney U test, when necessary) was used 


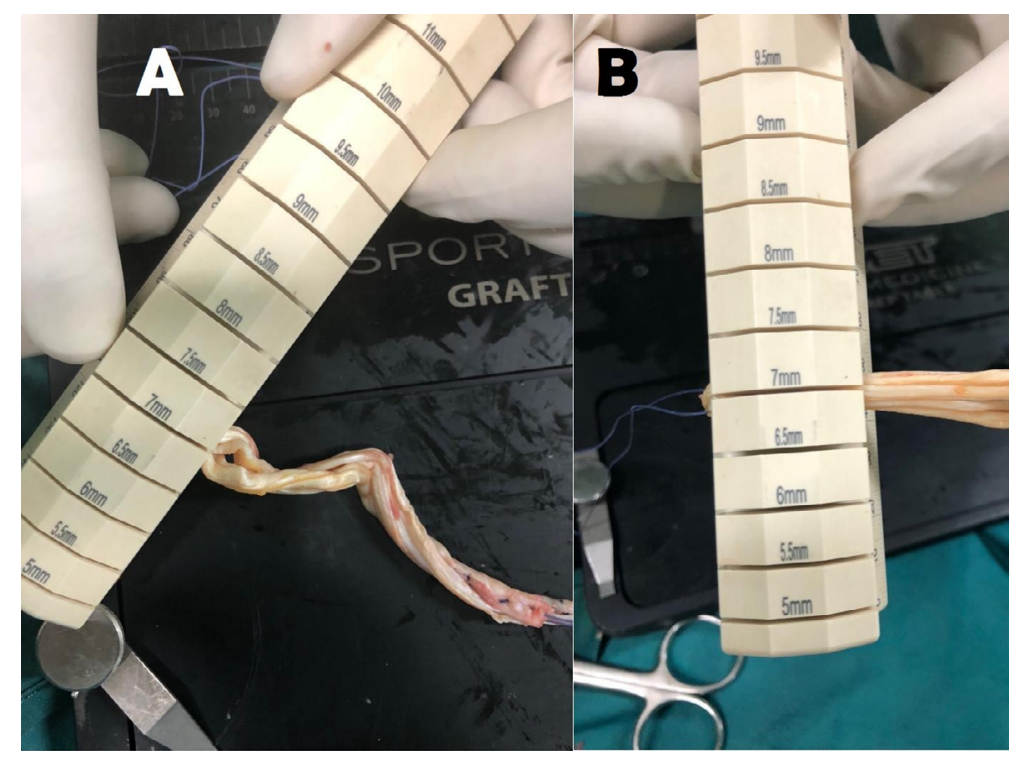

Figure 1. Assessment of the width of the graft

A: The 4-layer graft following extraction (did not pass through the $7 \mathrm{~mm}$ measure); B: The same graft after the preparation by dry gauze (passed through the $7 \mathrm{~mm}$ measure).

to compare the obtained data between the two groups. The qualitative results obtained from the anterior drawer test, the Lachman test, and the pivot-shift-test (positive or negative) were compared with the Chi-squared test (or the Fisher test, when necessary). Data analyses were performed using the SPSS V. 20 and the P value of lower than 0.05 was deemed significant.

\section{Results}

Each group comprised of 16 patients (total Mean \pm SD age: $25.6 \pm 4.3$ years). All patients were male; the causes of the ACL tears/ruptures were as follows: football practice $(n=24)$, volleyball practice $(n=2)$, accident $(n=3)$, and falling from a height $(n=4)$. Furthermore, the Mean \pm SD time of admittance after the infliction of injury was $12 \pm 2.6$ months. The Mean \pm SD BMI of patients was $26.2 \pm 2.4$ and $27.2 \pm 1.8$ in the dry gauze and wet gauze groups, respectively (Table 1 ).

Figure 2 presents the width of the 4-layered grafts after extraction. The Mean $\pm \mathrm{SD}$ width of the 4-layered extracted grafts was $7.44 \pm 0.54 \mathrm{~mm}$ and $7.41 \pm 0.33 \mathrm{~mm}$ in the dry gauze and wet gauze groups, respectively. However, these values did not significantly differ $(\mathrm{P}=0.96)$. Averagely, the grafts spent 25.3 minutes and 18.1 minutes in the dry and wet preparations, respectively. After traction, the average graft width in the dry gauze group was re-

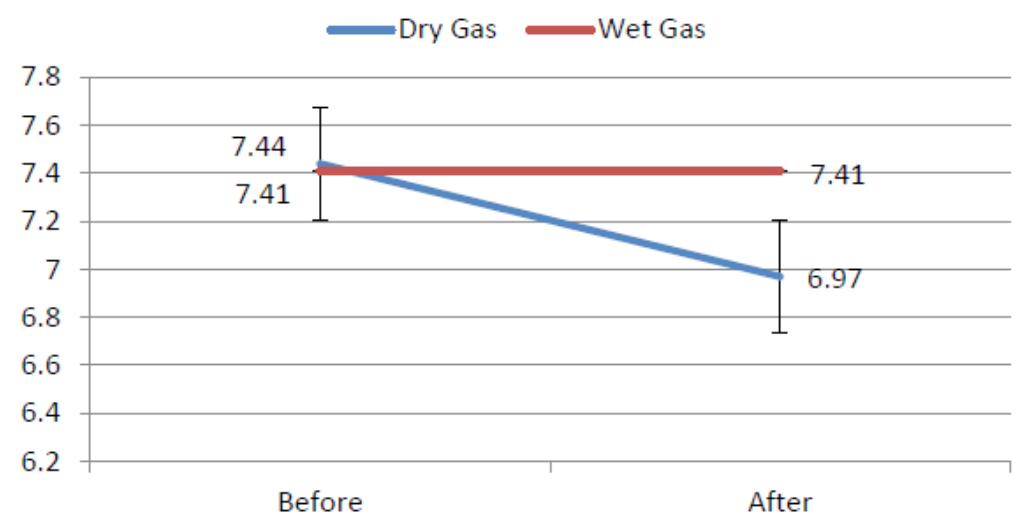

Figure 2. Alterations in graft width before and after the traction, by the preparation methods 
Table 1. Demographic information of the two study groups

\begin{tabular}{ccc}
\hline & \multicolumn{3}{c}{ Mean \pm SD / No. (\%) } \\
\cline { 2 - 3 } Variable & Wet Gauze Preparation & Dry Gauze Preparation \\
\hline Mean age (years) & $25.2 \pm 3.1$ & $25.4 \pm 3.6$ \\
\hline Sport injury & $13(81.25)$ & $12(75)$ \\
\hline Accidents injury & $1(6.2)$ & $2(12.5)$ \\
\hline Falling from a height & $2(12.5)$ & $2(12.5)$ \\
\hline BMI (kg/m²) & $27.2 \pm 1.8$ & $26.2 \pm 2.4$ \\
\hline Time of injury (month) & $12.7 \pm 1.4$ & $12.4 \pm 2.1$ \\
\hline
\end{tabular}

duced to $6.97 \pm 0.62 \mathrm{~mm}$. The traction did not change the graft width of the wet gauze group. The Mann-Whitney U test revealed a significant difference in the width changes between the two groups $(\mathrm{P}=0.032)$, following the application of traction. Besides, the paired t-test revealed that the alteration in width by about $0.5 \mathrm{~mm}$ in the dry gauze group was statistically significant $(\mathrm{P} \leq 0.001)$. The graft width remained constant in the wet gauze group.

After 6 months, the clinical evaluation of the patients revealed that four patients did not exhibit a certain endpoint in the Lachman test. Out of these four patients, two belonged to the dry gauze group and two belonged to the wet gauze group, also, two claimed that they were unable to run. Moreover, the pivot-shift-test was positive in five patients, two of which belonged to the dry gauze group and three to the wet gauze group. Besides, the anterior drawer test was positive in two patients of the dry gauze group and three patients of the wet gauze group.

\section{Discussion}

This study evaluated the impacts of the wet and dry gauze methods of hamstring graft preparation on ACL reconstruction surgery. Preparation with dry gauzes decreased the graft width, requiring narrower tunnels to be dug in the tibia and femur bones. Also, the traction did not affect the width of grafts prepared by the wet gauze method. However, the use of dry gauze can cause side effects, including the increased risk of infection and tendon necrosis; we have not observed such complications, in this study, but they need to be studied in a larger sample size.

The hamstring width varies depending on the age of the individual $[16,17]$. Also, this value is affected by anthropometric parameters [18, 19]. Various studies have evaluated the impact of hamstring graft size on the re- vision of ACL reconstructive surgery. The type of graft (allograft or autograft) does not affect the final results of ACL reconstruction [20].

However, the graft inclination angle technique and the methods of preparation can significantly impact the final results $[14,15,21]$. In many studies, the small sizes of the graft are associated with higher revision in ACL reconstruction [19-23]. In such studies, grafts with widths of less than $8 \mathrm{~mm}$ faced a higher chance of failure, compared with the 5 and 6-strand grafts [22-25]. Therefore, the increase in graft width is not directly correlated with better clinical outcome in ACL reconstruction surgery [26, 27].

An array of factors affect the outcome of ACL reconstruction surgery. In a study on 786 patients with torn ACL, the larger widths of the hamstring grafts were not directly correlated with the decreased revision. However, age was the most prominent factor in this regard [27]. Also, larger graft widths may result in more severe arthrofibrosis and worsen the functional outcomes in patients [28]. Although smaller graft widths are associated with the higher chances of recurrent ACL torsion, larger widths carry an increased risk of impingement. Besides, the larger widths of graft require larger tunnels, which cause greater bone damage. Hence, the use of smaller, more robust grafts is always optimal.

The durability of a tendon graft relies on the collagenous content of the graft [28]. The physical shrinking of a graft does not affect the collagen content and keeps the same durability [28]. It is considered optimal to keep the durability of a graft constant and simultaneously provide methods that require smaller tunnels created within the bones to achieve better clinical outcomes [28, 29]. Also, due to a very high osmotic potential within tendons, 
shrunk tendons reabsorb fluid and retain their initial size rapidly [28, 29].

Graft ligamentization is another issue in ACL reconstruction surgery. This process is time-consuming and any interference during this time may lead to tunnel widening [29]. Tunnel graft mismatch, especially at the entry point of the graft into the tunnel, leads to tunnel widening due to the windshield effect, which in turn results in surgical failure. Various biomechanical factors, such as the movement of the graft within the tunnel, drillinginduced bone necrosis, and the shape of the tunnel opening may cause tunnel widening; these factors result in the accumulation of synovium within the tunnel and subsequent widening. The shrinkage of grafts prepared with the dry gauze method leads to the drilling of narrower tunnels, which will be filled out with the graft after the absorption of fluids. Thus, the dry gauze method reduces the chance of synovial accumulation within the tunnel and subsequent tunnel widening [30].

The short follow-up period was the main limitation of the present study. Although after the 6-month follow-up only two patients of the dry gauze group had nonfunctional ACLs, the functional outcome of the reconstructive surgery could not be evaluated based on scoring methods. Thus, the possible negative outcomes of graft shrinking on graft longevity remain undetermined. Long-term follow-ups and clinical evaluations are currently underway for the patients enrolled in this study.

\section{Conclusion}

Hamstring graft preparation using the dry gauzes technique procures the need for a narrower tunnel in the tibia and femur. It seems that a relative increase in graft size after the resorption of fluids decreases the tunnel-graft mismatch.

\section{Ethical Considerations}

\section{Compliance with ethical guidelines}

The study was confirmed by the Ethics Committee of Urmia University of Medical Sciences.

\section{Funding}

This research did not receive any specific grant from funding agencies in the public, commercial, or not-profit sectors.

\section{Authors' contributions}

All authors contributed in preparing this research.

\section{Conflict of interest}

The authors declared no conflict of interest.

\section{References}

[1] Park SY, Oh H, Park S, Lee JH, Lee SH, Yoon KH. Factors predicting hamstring tendon autograft diameters and resulting failure rates after anterior cruciate ligament reconstruction. Knee Surg Sports Traumatol Arthrosc. 2013; 21(5):1111-8. [DOI:10.1007/s00167-012-2085-4] [PMID]

[2] Ejerhed L, Kartus J, Sernert N, Köhler K, Karlsson J. Patellar tendon or semitendinosus tendon autografts for anterior cruciate ligament reconstruction? A prospective randomized study with a two-year follow-up. Am J Sports Med. 2003; 31(1):19-25. [DOI:10.1177/03635465030310011401] [PMID]

[3] Feller JA, Webster KE. A randomized comparison of patellar tendon and hamstring tendon anterior cruciate ligament reconstruction. Am J Sports Med. 2003; 31(4):564-73. [DOI:1 0.1177/03635465030310041501] [PMID]

[4] Freedman KB, D'Amato MJ, Nedeff DD, Kaz A, Bach BR Arthroscopic anterior cruciate ligament reconstruction: A metaanalysis comparing patellar tendon and hamstring tendon autografts. Am J Sports Med. 2003; 31(1):2-11. [DOI:10.1 177/03635465030310011501] [PMID]

[5] Laxdal G, Kartus J, Hansson L, Heidvall M, Ejerhed L, Karlsson J. A prospective randomized comparison of bone-patellar tendon-bone and hamstring grafts for anterior cruciate ligament reconstruction. Arthroscopy. 2005; 21(1):34-42. [DOI:10.1016/j.arthro.2004.09.014] [PMID]

[6] Hamner DL, Brown CH, Steiner ME, Hecker AT, Hayes WC. Hamstring tendon grafts for reconstruction of the anterior cruciate ligament: Biomechanical evaluation of the use of multiple strands and tensioning techniques. J Bone Joint Surg Am. 1999; 81(4):549-57. [DOI:10.2106/00004623199904000-00013] [PMID]

[7] Wilson TW, Zafuta MP, Zobitz M. A biomechanical analysis of matched bone-patellar tendon-bone and double-looped semitendinosus and gracilis tendon grafts.Am J Sports Med. 1999; 27(2):202-7. [DOI:10.1177/03635465990270021501] [PMID]

[8] Maletis GB, Cameron SL, Tengan JJ, Burchette RJ. A prospective randomized study of anterior cruciate ligament reconstruction: A comparison of patellar tendon and quadruple-strand semitendinosus/gracilis tendons fixed with bioabsorbable interference screws. Am J Sports Med. 2007 35(3):384-94. [DOI:10.1177/0363546506294361] [PMID]

[9] Sajovic M, Vengust V, Komadina R, Tavcar R, Skaza K. A prospective, randomized comparison of semitendinosus and gracilis tendon versus patellar tendon autografts for anterior cruciate ligament reconstruction: Five- 
year follow-up. Am J Sports Med. 2006; 34(12):1933-40. [DOI:10.1177/0363546506290726] [PMID]

[10] Samuelsson K, Andersson D, Karlsson J. Treatment of anterior cruciate ligament injuries with special reference to graft type and surgical technique: An assessment of randomized controlled trials. Arthroscopy. 2009;25(10):1139-74. [DOI:10.1016/j.arthro.2009.07.021] [PMID]

[11] Tuman JM, Diduch DR, Rubino LJ, Baumfeld JA, Nguyen HS, Hart JM. Predictors for hamstring graft diameter in anterior cruciate ligament reconstruction. Am J Sports Med. 2007; 35(11):1945-9. [DOI:10.1177/0363546507304667] [PMID]

[12] Calvo R, Melean P, Figueroa D, Vaisman A, Scheu M, Figueroa F. Does patient weight and height correlate with the length and diameter of the semitendinosus graft? Rev Esp Cir Ortop Traumatol. 2011; 55(1):2-8. [DOI:10.1016/ S1988-8856(11)70273-5]

[13] Ma CB, Keifa E, Dunn W, Fu FH, Harner CD. Can pre-operative measures predict quadruple hamstring graft diameter? Knee. 2010; 17(1):81-3. [DOI:10.1016/j.knee.2009.06.005] [PMID]

[14] Schwartzberg R, Burkhart B, Lariviere C. Prediction of hamstring tendon autograft diameter and length for anterior cruciate ligament reconstruction. Am J Orthop (Belle Mead NJ). 2008; 37(3):157-9. https://europepmc.org/article/ med/18438472

[15] Treme G, Diduch DR, Billante MJ, Miller MD, Hart JM. Hamstring graft size prediction: A prospective clinical evaluation. Am J Sports Med. 2008; 36(11):2204-9. [DOI:10.1177/0363546508319901] [PMID]

[16] Calvo R, Figueroa D, Figueroa F, Vaisman A, SchmidtHebbel A, Morales N, et al. Five-strand hamstring autograft versus quadruple hamstring autograft with graft diameters 8.0 millimeters or more in anterior cruciate ligament reconstruction: Clinical outcomes with a minimum 2-year followup. Arthroscopy. 2017; 33(5):1007-13. [DOI:10.1016/j.arthro.2016.10.028] [PMID]

[17] Lavery KP, Rasmussen JF, Dhawan A. Five-strand hamstring autograft for anterior cruciate ligament reconstruction. Arthrosc Tech. 2014; 3(4):e423-e6. [DOI:10.1016/j. eats.2014.01.013] [PMID] [PMCID]

[18] Lee RJ, Ganley TJ. The 5-strand hamstring graft in anterior cruciate ligament reconstruction. Arthrosc Tech. 2014; 3(5):e627e31. [DOI:10.1016/j.eats.2014.07.002] [PMID] [PMCID]

[19] Magnussen RA, Lawrence JTR, West RL, Toth AP, Taylor DC, Garrett WE. Graft size and patient age are predictors of early revision after anterior cruciate ligament reconstruction with hamstring autograft. Arthroscopy. 2012; 28(4):526-31. [DOI:10.1016/j.arthro.2011.11.024] [PMID]

[20] Moghtadaee M, Farahini H, Jahansouz A, Mokhtari T, Nabi R. Comparative Study of Treatment Results for Anterior Cruciate Ligament Reconstruction With Allograft and Auto Graft. J Res Orthop Sci. 2014; 1(3):13-6. http://jros.iums. ac.ir/article-1-126-en.html

[21] Moghtadaei M, Abedi M, Yeganeh A, Yahyazadeh H, Hossienzadeh N, Moeini J, et al. Graft inclination angle is associated with the outcome of the anterior cruciate ligament reconstruction. J Res Orthop Sci. 2018; 5(4):e83764. [DOI: 10.5812/soj.83764]
[22] Kamien PM, Hydrick JM, Replogle WH, Go LT, Barrett GR. Age, graft size, and Tegner activity level as predictors of failure in anterior cruciate ligament reconstruction with hamstring autograft. Am J Sports Med. 2013; 41(8):1808-12. [DOI:10.1177/0363546513493896] [PMID]

[23] Ho B, Edmonds EW, Chambers HG, Bastrom TP, Pennock AT. Risk factors for early ACL reconstruction failure in pediatric and adolescent patients: A review of 561 cases. J Pediatr Orthop. 2018; 38(7):388-92. [DOI:10.1097/ BPO.0000000000000831] [PMID]

[24] Krishna L, Panjwani T, Mok YR, Wong FKL, Singh A, Toh SJ. Use of the 5-strand hamstring autograft technique in increasing graft size in anterior cruciate ligament reconstruction. Arthroscopy. 2018; 34(9):2633-40. [DOI:10.1016/j. arthro.2018.03.026] [PMID]

[25] Prodromos C, Joyce B. Five-strand hamstring anterior cruciate ligament reconstruction: Presentation of a new technique with better stability at 7-to 9-year follow up than 4 strand. Tech Orthop. 2005; 20(3):192-3. [DOI:10.1097/01. bto.0000177264.50076.b2]

[26] Brown Jr CH. Editorial commentary: How to increase hamstring tendon graft size for anterior cruciate ligament reconstruction. Arthroscopy. 2018; 34(9):2641-6. [DOI:10.1016/j. arthro.2018.06.014] [PMID]

[27] Wernecke GC, Constantinidis A, Harris IA, Seeto BG, Chen DB, MacDessi SJ. The diameter of single bundle, hamstring autograft does not significantly influence revision rate or clinical outcomes after anterior cruciate ligament reconstruction. Knee. 2017; 24(5):1033-8. [DOI:10.1016/j. knee.2017.05.011] [PMID]

[28] Su AW, Storey EP, Lin SC, Forst B, Lawrence JT, Ganley $\mathrm{TJ}$, et al. Association of the graft size and arthrofibrosis in young patients after primary anterior cruciate ligament reconstruction. J Am Acad Orthop Surg. 2018; 26(23):e483-e9. [DOI:10.5435/JAAOS-D-17-00177] [PMID]

[29] Hofbauer M, Soldati F, Szomolanyi P, Trattnig S, Bartolucci $\mathrm{F}, \mathrm{Fu} \mathrm{F}$, et al. Hamstring tendon autografts do not show complete graft maturity 6 months postoperatively after anterior cruciate ligament reconstruction. Knee surg sports traumatol arthrosc. Knee Surg Sports Traumatol Arthrosc. 2019; 27(1):130-6. [DOI:10.1007/s00167-018-5033-0] [PMID] [PMCID]

[30] Schüttler KF, Hoeger A, Heyse TJ, Figiel J, Timmesfeld N, Stein $\mathrm{T}$, et al. Femoral tunnel widening is associated with tunnel malposition but not with clinical failure after medial patellofemoral ligament reconstruction with a free gracilis tendon graft. Arch Orthop Trauma Surg. 2018; 138(7):979-84. [DOI:10.1007/s00402-018-2923-z] [PMID] 